\title{
Improvement of the Liver Steatosis Diagnostics Algorithm with Application of the Ultrasound Wave Attenuation Coefficient Estimation
}

\author{
Borsukov $\mathrm{AV}^{*}$ and Venidiktova D Yu \\ Smolensk State Medical University, Russia
}

Submission: January 09, 2018; Published: July 16, 2018

*Corresponding author: Borsukov AV, Problem scientific-research Laboratory Diagnostic researches and miniinvasive technologies, Smolensk State Medical University, Russia, Email: bor55@yandex.ru

Summary

Pilot results of new quantifying ultrasound methodic of liver steatosis evaluation in $\mathrm{dB} / \mathrm{cm}$ are presented in this article. Main stages of the methodic standardization are tested in control group of patients $(n=90)$. Liver biopsy $(n=40)$ and dual-energy X-ray absorbtiometry in "Whole body" regime $(n=148)$ were reference methods in clinical group of patients $(n=148)$ with overweight and non-alcoholic fatty liver disease. The correlation of ultrasound liver steatosis diagnostics and liver biopsy was $\mathrm{r}=0.86$ at $\mathrm{S} 0$ and $\mathrm{r}=0.84$ at $\mathrm{S} 3$.

Keywords: Ultrasound diagnostics; Liver steatosis; Liver steatosis quantifying evaluation

\section{Relevance of the Problem}

Steatosis, non-alcoholic steatohepatitis (NASH) and liver cirrhosis are pathological conditions, united by a single nosological form - non-alcoholic fatty liver disease (NAFLD). The predominant part of NAFLD cases is associated with the classical variant of metabolic syndrome. Some authors suggest that NAFLD should be considered as one of the components of the metabolic syndrome [1-3]. The incidence of NAFLD varies in different countries, an average of $20-33 \%$ of cases in the adult population $[4,5]$. Currently, a large number of clinical and laboratory and instrumental methods of research are used to diagnose the NAFLD: collection of complaints, life anamnesis, disease history; physical examination; biochemical blood test ( $\uparrow$ ALT, AST, GGT, APF, bilirubin); lipid profile ( $\uparrow$ TG, $\downarrow$ HDL); liver ultrasound, incl. elastometry (has advantages at the stage of fibrosis and cirrhosis, CT, liver MRI, liver biopsy ("gold standard"), histological scales (NAS, SAF, fibrosis score, BARD), Fibro Max tests, Fibro Meter, insulin resistance diagnostics [6]. But these methods have a number of disadvantages: high cost, low specificity, low sensitivity of the method, the need for invasive and mini-invasive interventions, etc., which do not allow to carry out the necessary research in connection with patient-, operative-dependent factors and, accordingly, do not provide a quantitative assessment of hepatic steatosis with NAFLD, which is necessary for the correct formulation of diagnosis and adequate therapy.
Aim

Development and clinical evaluation of a new ultrasound (US) technique for the quantitative determination of liver steatosis by determining the attenuation coefficient (AC) of ultrasound in patients with NAFLD.

\section{Material and Methods}

Since 2015, on the basis of the Problem scientificresearch laboratory "Diagnostic researches and mini-invasive technologies" of the Smolensk state medical university, a study of patients with excessive body weight has been started using a new quantitative ultrasound for the diagnosis of hepatic steatosis. The principle of ultrasound wave attenuation coefficient is at the base of the new ultrasound method of liver steatosis quantitative assessment. The factor of linear attenuation of ultrasound in tissues makes it possible to quantitatively determine the degree of attenuation in $\mathrm{dB} / \mathrm{cm}$, which makes it possible to determine the severity of fatty hepatosis. The main stages of the procedure standardization were worked out in the control group ( $n=90)$, patients aged 40-49 years ( $n=27), 50-59$ years $(n=41), 60-69$ years $(n=22)$. The criteria for excluding patients from the control group were: excessive body weight or obesity of any degree, the presence of ultrasound signs of hepatic steatosis in B-mode, changes in biochemical blood test parameters (ALT, AST, GGT, cholesterol, triglycerides, total and direct bilirubin). 


\section{Current Research in Diabetes \& Obesity Journal}

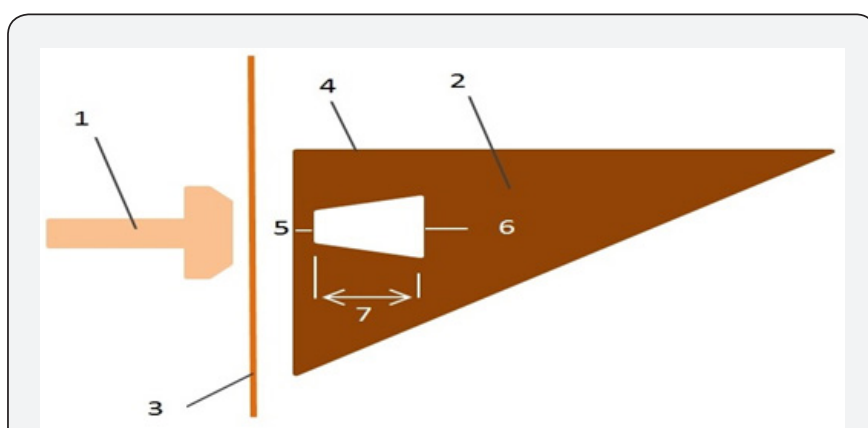

Figure 1: Scheme of evaluation of the attenuation coefficient in the liver ultrasound.1-ultrasound transducer, 2-liver, 3-skin, 4-liver capsule, 5-base "I", 6-base "II", 7-length.

The standard methodology for the quantitative ultrasound assessment of liver steatosis is presented in Figure 1. The most optimal measurement is in the VI-VII segments in diffuse liver diseases. The active zones were located at a distance of at least $20 \mathrm{~mm}$ from the capsule, not less than $30 \mathrm{~mm}$ long; the size of the smaller base directed to the liver capsule is not less than $10 \mathrm{~mm}$ and the size of the base of the core is not less than $15 \mathrm{~mm}$. We used liver biopsy $(n=40)$ under ultrasound control (G18-G16 trepan biopsy needle with $15 \mathrm{~mm}$ long biopsy) and dual-energy X-ray absorptiometry in the "Whole body" mode $(n=148)$ as reference methods of evaluation. In the framework of this study, we interviewed all patients $(\mathrm{n}=148)$, whether they agree on a liver biopsy under ultrasound control or not. $73 \%$ of patients $(n=108)$ refused this procedure even after a conversation with the doctor, at which $65 \%$ of patients ( $n=96)$ refused immediately, without hesitation. $27 \%$ of patients $(n=40)$ agreed to this procedure after talking with a doctor; and only $5 \%$ of all subjects $(n=7)$ agreed immediately.

As an alternative reference method of research, we used a dual-energy X-ray absorptiometry in the "Whole body" mode, which allows us to estimate the overall presence of excess body weight, obesity in the given patient by calculating not only the body mass index (BMI), but also the fat mass index (FMI), as more specific in the evaluation of this pathology [7-9]. This method allows evaluating the following indicators, together providing qualitative and quantitative assessment of the patient with NAFLD, which is a factor in the development of this pathology:

a. Composition of the whole body and by regions.

b. Percentage of fat, muscle and bone content.

c. The index of fat, muscle and bone mineral mass.

d. Muscle-skeletal index.

e. Basic metabolic rate.

f. Percentage of fat in the android/gynoid areas.

All patients were examined according to a standard diagnostic algorithm:

a) Liver ultrasound (B-mode). b) Liver ultrasound with quantitative determination of ultrasound wave attenuation coefficient.

c) Dual-energy X-ray absorptiometry in the "Whole body" mode.

d) Liver biopsy under ultrasound. Using the SAF scale, the characteristics of a histological specimen of a liver biopsy specimen were evaluated, such as the severity of steatosis, the presence of balloon dystrophy and lobular inflammation, as well as the stage of liver fibrosis in the form of the S2A1F0 index. The liver was evaluated as S0, S1, S2, S3, depending on the degree of changes: $<5 \%, 5-33 \%, 33-66 \%,>66 \%$ of the changed hepatocytes, respectively [10]. All histological preparations of liver biopsy specimens were coordinated in a single system with echograms examining the ultrasonic wave attenuation coefficient in the liver for subsequent evaluation of the correlation relationships of the two methods of investigation.

e) Statistical processing of data with the determination of the correlation relationship was carried out in the program STATISTICA 6.0. The following statistical hypotheses were proposed: H0: in pair wise comparison, the informative nature of the methods (the number of patients who received identical data identical to the histological conclusion) is the same in the same time periods; H1: the informative nature of methods is significantly different. The results of a pair wise comparison of the informative nature of the methods at different stages of patient observation were considered statistically significant at $\mathrm{p}<0.05$.

\section{Results and Discussion}

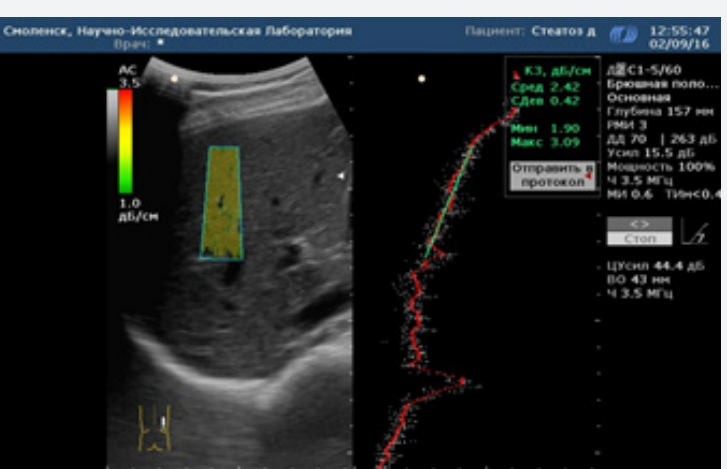

Figure 2a: US image of liver in a mode of ultrasound wave attenuation coefficient evaluation: a weakly expressed liver steatosis $(\mathrm{C} 3=2,42 \mathrm{~dB} / \mathrm{cm})$.

Various stages of NAFLD were identified in the histological study of liver biopsy materials. Evaluation of the results was carried out according to the SAF scale for semi-quantitative evaluation of gravity and the stage of NAFLD. We evaluated the correlation of the histological evaluation of liver biopsy samples with the ultrasound wave attenuation coefficient (Figure 2a, 2b \& Figure 3a, 3b). All patients in the clinical group who underwent liver biopsy under the ultrasound were divided into groups, depending on the severity of fat changes 


\section{Current Research in Diabetes \& Obesity Journal}

in hepatocytes according to the SAF scale. Thus, by performing an analysis of the comparison of histological specimens of liver biopsy samples and ultrasound data of the quantitative evaluation of the ultrasound wave attenuation in $\mathrm{dB} / \mathrm{cm}$, it can be concluded that the correlation between liver biopsy and ultrasound wave attenuation coefficient evaluation is sufficient for in-formativeness at the initial and significant stages of liver steatosis ( $\mathrm{S} 0 \mathrm{r}=0.86$; $\mathrm{S} 3 \mathrm{r}=0.84$ ). In stages $\mathrm{S} 1$ and $\mathrm{S} 2$, the informativity is lower, and it requires the introduction of more patients in the study protocols, carrying out liver elastography and increasing the number of liver biopsies in clinical groups.

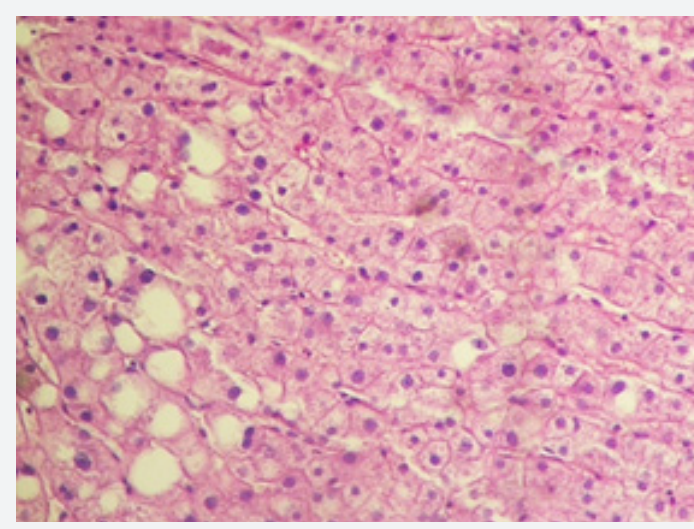

Figure 2b: Histopreparation of the liver biopsy: mildly expressed fatty degeneration of hepatocytes in a patient with NAFLD. Color: h-e, x 200.

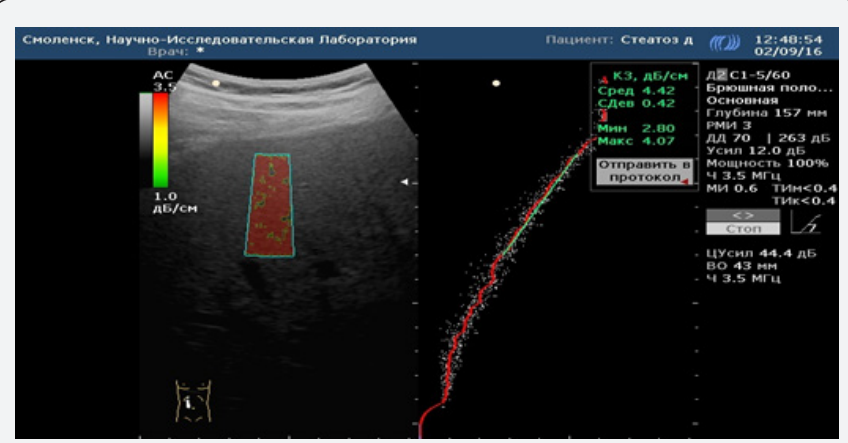

Figure 3A: US image of liver in a mode of ultrasound wave attenuation coefficient evaluation: expressed liver steatosis (C3 $=4.42 \mathrm{~dB} / \mathrm{cm})$.

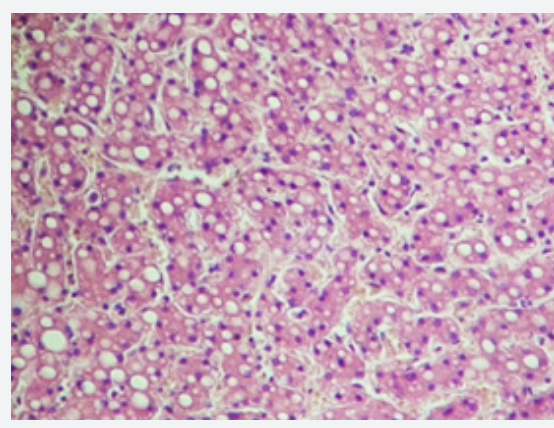

Figure 3B: Histopreparation of the liver biopsy: expressed fatty degeneration of hepatocytes in a patient with NAFLD. Color: h-e, $\times 200$.
In assessing the comparison of histological specimens of liver biopsy specimens and dual-energy X-ray absorptiometry in the "Whole body" mode, the situation is different: at all stages of liver steatosis, we see a good correlation of the data (from $r=0.86$ to $r=0.93$ ). This confirms the thesis of European scientific studies on the good applicability of this technique in the diagnosis of hepatic steatosis [10]. Based on the above data, we have a full justification for replacing the two-energy X-ray absorptiometry in the "Whole body" mode with the ultrasound wave attenuation coefficient evaluation for the diagnosis of liver steatosis of extreme grades: with minimal and maximum changes. In using the ultrasound wave attenuation coefficient evaluation in identifying intermediate stages of hepatic steatosis, there is a clear direction in the recruitment of a clinical material with a unified statistical evaluation, which is likely to increase the informative value of the quantitative ultrasound assessment of hepatic steatosis [11].

\section{Conclusion}

New ultrasound technique with a quantitative assessment of hepatic steatosis in $\mathrm{dB} / \mathrm{cm}$ is a promising trend in the diagnosis of steatosis; Correlation of ultrasound diagnosis of steatosis with biopsy at stage S0 corresponds to $r=0.86$; at stage S3 corresponds to $r=0.84$, which indicates that the method is highly informative; "The whole body" can be changed on the ultrasound wave attenuation coefficient evaluation in the diagnosis of liver steatosis in the presence of clinical necessity.

\section{References}

1. Bueverov AO, Bogomolov PO, Maevskaya MV (2007) Pathogenetic treatment of non-alcoholic steatohepatitis, justification, effectiveness, safety. Ter arch 8: 88-92.

2. Bueverov AO, Bogomolov PO (2009) Nonalcoholic fatty liver disease: rationale for pathogenetic therapy. Klinicheskie perspectivi gastroenterologii i gepatologii 1: 3-9.

3. Tarantino G, Saldalamacchia G, Conca P, Arena A (2007) Non-alcoholic fatty liver disease: further expression of the metabolic syndrome. J Gastroenterol Hepatol 22(3): 293-303.

4. Browning JD, Szczepaniak LS, Dobbins R, Nuremberg P, Horton JD, et al. (2004) Prevalence of hepatic steatosis in an urban population in the United States: impact of ethnicity. Hepatology 40(6): 1387-1395.

5. Clark JM, Brancati FL, Diehl AM (2003) The prevalence and etiology of elevated aminotransferase levels in the United States. Am J Gastroenterol 98(5): 960-967.

6. Borsukov AV, Morozova TG (2016) Clinical and diagnostic significance of multivariate evaluation of liver elastography in patients with diffuse liver disease. Russian Journal of Gastroenterology, Hepatology, Coloproctology 2-16. - T. 26. - №5. Appendix 48. Materials of 22 United Gastroenterological Week on October 3-5, Moscow, p. 105.

7. Borsukova MV, Borsukov AV, Venidiktova D Yu, Nozdrachev OV (2007) Diagnostic possibilities of dual-energy x-ray absorptiometry in the diagnostic algorithm of the metabolic syndrome. Meditsinskiy alfavit. Diagnosticheskaya radiologia. - 2-12. - №2. 9. M.K. Outes. The Use of DXA for Total Body Composition Analysis. Int Society for Clin Densitometry, pp. 36-38.

8. Gallagher D, Heymsfield SB, Heo M, Jebb SA, Murgatroyd PR, et al. (2000) Healthy percentage body fat ranges an approach for developing guidelines based on body mass index. Am J Clin Nutr 72(3): 694-701. 


\section{Current Research in Diabetes \& Obesity Journal}

9. Bedossa P, Consortium FLIP (2014) Utility and appropriateness for the fatty liver inhibition of progression (FLIP) algorithm and steatosis, activity, and fibrosis (SAF) score in the evaluation of biopsies of nonalcoholic liver disease. Hepatology 60(2): 565-575.

10. Ivashkin VT, Maevskaya MV, Zharkova MS, Tikhonov IN, Fedosina EA, et al. (2016) Algorithms for diagnosis and treatment in hepatology. Medpress-inform, Moscow, p. 155

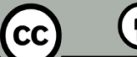

This work is licensed under Creative Commons Attribution 4.0 Licens

DOI: 10.19080/CRDOJ.2018.07.555722
11. Ivashkin VT, Drapkina OM, Shulpecova Yu O (2009) Diagnostics and treatment of non-alcoholic fatty liver disease (methodical recommendations). M : 000»Publishing House» M-Vesti «, Russia, p. 20.

\section{Your next submission with Juniper Publishers will reach you the below assets}

- Quality Editorial service

- Swift Peer Review

- Reprints availability

- E-prints Service

- Manuscript Podcast for convenient understanding

- Global attainment for your research

- Manuscript accessibility in different formats

( Pdf, E-pub, Full Text, Audio)

- Unceasing customer service

Track the below URL for one-step submission https://juniperpublishers.com/online-submission.php 